\title{
REPAIR OF DYSKINETIC OR AKINETIC LEFT VENTRICULAR ANEURYSM: RESULTS OBTAINED WITH A MODIFIED LINEAR CLOSURE
}

Lynda L. Mickleborough, MD

Susan Carson, AHT

Joan Ivanov, MSc

For related editorial, see p. 628 .
Objective: In patients with a dyskinetic or akinetic area of the left ventricle, controversy exists over who will benefit from resection. This study evaluates results achieved with a modified linear closure in 193 of 196 consecutive cases. Preoperative cases $(n=160$ [83\%]) were in functional class III or IV with congestive heart failure $(n=115[60 \%])$, angina $(n=108[56 \%])$, and syncope $(n=67[35 \%])$. The ejection fraction was $25 \% \pm 8 \%$, and echocardiography showed significant mitral regurgitation in $86(45 \%)$ patients. In patients with detailed wall motion analysis, 50 (57\%) were akinetic, and 37 (43\%) were dyskinetic.

Methods: Repair was completed on the beating heart to minimize ischemia and allow assessment of wall function and viability to guide resection and repair. Additional procedures included coronary artery bypass grafting $(\mathrm{n}=$ $175[91 \%])$, septoplasty $(n=24[12 \%])$, and arrhythmia ablation $(n=77$ [40\%]). Ventricular and mitral valve function were assessed by means of preoperative and/or postoperative gated acquisition scans in $171(90 \%)$ patients and Doppler echocardiograms in $170(88 \%)$ patients.

Results: Hospital mortality was low (5/193 [2.6\%]), although 34 (18\%) patients needed perioperative intra-aortic balloon pump support. Actuarial survival at 1 and 5 years was $91 \%$ and $84 \%$. Most late deaths were due to congestive heart failure. Seven patients required transplantation (interval, 36 \pm 32 months). As determined by multivariable analysis, factors predicting poor outcome at 5 years were preoperative mitral regurgitation of $2+$ or greater, congestive heart failure, and ventricular tachycardia. Among survivors, $126(80 \%)$ of 157 were in functional class I or II, and the average increase in ejection fraction postoperatively was $9.1 \% \pm 10.0 \%$. Postoperative echocardiograms in 70 patients with significant mitral regurgitation preoperatively showed improved valve function in $40(57 \%)$ of 70 patients.

Conclusions: We conclude that repair of dyskinetic or akinetic aneurysms by means of a modified linear closure plus septoplasty in selected patients can be accomplished in the beating heart with low operative mortality, provides good symptomatic relief and long-term survival, and is associated with objective evidence of improved left ventricular and mitral valve function. ( $\mathrm{J}$ Thorac Cardiovasc Surg 2001;121:675-82)
E or many years, left ventricular (LV) aneurysm resecF tion has been recommended in patients with coronary artery disease as a treatment for heart failure, angi-

From the University of Toronto, Toronto, Ontario, Canada.

Copyright (C) 2001 by The American Association for Thoracic Surgery

0022-5223/2001 $\$ 35.00+0 \quad \mathbf{1 2 / 1 / 1 1 2 6 3 3}$

doi: $10.1067 / \mathrm{mtc} .2001 .112633$ na, and thromboembolic complications or as an adjunct for therapy of ventricular arrhythmias. The original description of the procedure as applied to discrete dyskinetic aneurysms included excision of the thin-walled sack, leaving behind a rim of scar to facilitate closure, which was accomplished in a linear fashion. ${ }^{1}$ Modifications of the original technique have been advocated that include the purse-string technique of Jatene, ${ }^{2}$ the endoventricular circuloplasty of Dor and col- 
leagues, ${ }^{3}$ and the endoaneurysmorrhaphy technique originally described by Cooley. ${ }^{4}$ Controversy has existed over whether patients with less discrete akinetic aneurysms will benefit from wall excision and repair. ${ }^{5,6}$

Since 1983, we have used a modified linear closure technique for aneurysm repair in patients with both akinetic and dyskinetic aneurysms. ${ }^{7}$ This repair technique has been combined with patch septoplasty in selected cases. This report updates our experience and highlights long-term results achieved with this simple, reproducible technique. In this series we have used preoperative and postoperative multiple gated acquisition (MUGA) and echocardiographic data to provide objective evidence of improved LV and mitral valve function.

\section{Material and methods}

Patient population. Between 1983 and 1997, 196 consecutive patients underwent $L V$ aneurysm repair by a single staff surgeon (L.M.). In all but 3 cases (excluded from this analysis), tailored excision of scar was followed by a modified linear closure.

Patients were selected for operation. Gross chamber dilatation was not a contraindication so long as contractile function was preserved in some portion of the ventricle. Patients with severe right ventricular dysfunction or severe pulmonary hypertension and those with diffuse disease in all coronary distributions were considered to have inoperable disease. Associated severe mitral regurgitation (MR) was a relative contraindication.

The 193 patients ranged in age from 22 to 78 years (mean, $59 \pm 10$ years). There were 37 female (19\%) and 156 male $(81 \%)$ patients. The aneurysm was anterior in 174 $(90 \%)$ patients, posterior in $18(9 \%)$ patients, and lateral in $1(0.5 \%)$ patient. Significant calcification was present in 23 (12\%) patients. Major indications for operation were often multiple and included angina in 108 (56\%) patients, congestive heart failure in $115(60 \%)$ patients, and ventricular arrhythmias in $86(45 \%)$ patients. Most patients were in symptom class III (58 [30\%]) or IV (102 [53\%]) before the operation. Double- or triple-vessel disease was present in $158(82 \%)$ patients. The distribution of preoperative ejection fraction $(\mathrm{EF})$ is shown in Fig 1. One hundred eightyfour $(95 \%$ ) patients had an $\mathrm{EF}$ of less than $40 \%$ (mean $\mathrm{EF}$, $25 \% \pm 8 \%$. Significant MR was present in $86(45 \%)$ patients: $2+$ in $60(31 \%)$ patients; $3+$ in 19 (10\%) patients; and $4+$ in $7(4 \%)$ patients.

Since 1988, detailed wall-motion analysis of the ventriculogram was possible in 87 patients by using a center-line method. ${ }^{5}$ Aneurysms were classified as dyskinetic if absolute motion of contiguous chords was less than 1 and akinetic if equal to 1 by this method. Of patients analyzed, 37 (43\%) had dyskinesia, and 50 (57\%) had akinesia. The extent of noncontracting muscle or asynergy was calculated as the percentage length of the LV perimeter showing a fractional shortening below 2 SDs from normal mean values. ${ }^{5}$ The mean asynergy was $58 \pm 16$ for akinetic and $60 \pm 12$ for dyskinetic aneurysms.

Unfortunately, in these patients biplane angiograms were not always done in referring institutions to allow accurate calculation of ventricular volumes. Of 174 patients with anterior aneurysms, assessment of ventricular size was possible in 128 patients on the basis of echocardiographic determination of end-diastolic dimension in 57 patients or analysis of the ventriculogram in 71 patients. Ventricular volume was grossly enlarged in 80 (63\%) of 128 patients (end-diastolic dimension $>63 \mathrm{~mm}$ or end-diastolic volume index $>160 \mathrm{~mL} / \mathrm{m}^{2}$ ).

Operative procedure: Tailored scar excision and modified linear closure. With the patient supported on normothermic cardiopulmonary bypass, the heart was carefully examined. In many patients it was not possible, on the basis of ventriculography or echocardiography, to determine whether akinesis or dyskinesis corresponds to an area of hibernating myocardium that will benefit from revascularization or to an area of scarred, thinned myocardium that should be resected. Viability studies have been used to try to determine which patients will most benefit from revascularization, ${ }^{8,9}$ but in our opinion, the decision of whether to revascularize or to excise a portion of nonfunctioning wall is best made at the time of the operation. In either case, surgical treatment has something to offer.

If the area of previous infarction consists of a mixture of viable muscle and scar and there is doubt about the extent of thinning, we avoid insertion of a ventricular vent, which may disrupt and embolize intraventricular clot. In such cases we recommend aspiration with an 18-gauge needle to assess wall thickness. Once significant thinning of the area has been confirmed, a small incision is made. Any clot present is carefully removed. With the unloaded heart open and beating, the surrounding wall is palpated, and its ability to contract (regional wall thickening) can be reliably assessed. All thinned, nonfunctioning portions of the wall are considered for resection.

The size and shape of the LV cavity is evaluated. Excision is planned to remove as much nonfunctioning wall as possible while restoring ventricular size and shape toward normal conditions by using the modified linear closure, as previously described. ${ }^{7}$ In many cases the excised specimen is composed of a mixture of infarcted and viable muscle, and repair sutures are often placed through relatively thick areas of myocardium. Sutures are placed further apart on the tissue edges than on the felt strips so that the length of the incision is plicated in the closure. This helps to restore the shape of the ventricle toward normal conditions.

In most patients with an anterior aneurysm, scarring of the septum is observed. However, only in cases in which a major portion of the septum is not only scarred but also thinned and aneurysmal is a septoplasty performed, as previously described..$^{10}$ The anterior edge of the patch is incorporated into the ventricular closure. Once ventricular repair has been completed, bypass grafting is carried out when indicated, including a graft to the proximal left anterior descending 
artery whenever possible. To perform grafting, we applied a crossclamp. Retrograde cardioplegia is used for protection of the left ventricle, and antegrade cardioplegia or infusion down a right graft is used to protect the right ventricle. In patients with ventricular arrhythmias, map-directed ablation or visually directed septal endocardial excision and cryoablation at the periphery have been carried out, as previously described. ${ }^{11}$

Follow-up. Follow-up was completed in 1998 by means of telephone contact with patients and referring physician or office visits when indicated. Preoperative and postoperative MUGA scans were done in 171 (89\%) patients, with LVEF calculated by means of computerized analysis. Doppler echocardiograms were done in $170(88 \%)$ patients to assess MR. In 123 (64\%) patients both preoperative and postoperative studies were performed.

Statistical analysis. The SAS (SAS Institute, Inc, Cary NC) and BMDP (BMDP Software, Los Angeles, Calif) programs were used for statistical analysis. Patient characteristics were compared by means of the $t$ test for continuous variables and the $\chi^{2}$ or Fisher exact test for categoric variables. Results are presented as mean \pm SD in the text and tables and mean $\pm \mathrm{SE}$ in the figures. Actuarial survival was calculated by the Kaplan-Meier statistic. A Wilcoxon test was used to evaluate differences in survival among subgroups of patients. A good long-term result, defined as 5-year survival without the need for transplantation or repeated hospitalizations for congestive heart failure, was evaluated multivariately by a Cox proportional hazards model with the following building strategy. Variables with a univariate $P$ value of less than .25 or those of known biologic importance but failing to meet the critical $\alpha$ level were submitted for consideration to the multivariate analysis by using stepwise selection.

\section{Results}

At the operation, associated cardiac procedures included clot removal ( $\mathrm{n}=55$ [29\%]), patch septoplasty $(\mathrm{n}=24[12 \%])$, arrhythmia ablation $(\mathrm{n}=77[40 \%])$, and CABG ( $\mathrm{n}=175$ [91\%]; average, $2.9 \pm 1.0$ grafts per patient). In $15(7.8 \%)$ patients the entire procedure was carried out on the beating heart. In the remaining 178 patients, the average crossclamp time was only 60 \pm 24 minutes. The average pump time was $174 \pm 56$ minutes. All patients were successfully weaned from bypass, but $108(56 \%)$ patients required inotrope support, and 34 (18\%) patients required an intra-aortic balloon pump.

There were 5 hospital deaths (mortality, 2.6\%). Two deaths were related to adult respiratory distress syndrome in patients receiving amiodarone. ${ }^{12}$ Three others were related to congestive heart failure and ventricular arrhythmias. Three (1.6\%) patients had perioperative myocardial infarctions. Four $(2.1 \%)$ patients were reoperated on for bleeding. There were $2(1.0 \%)$ ster-

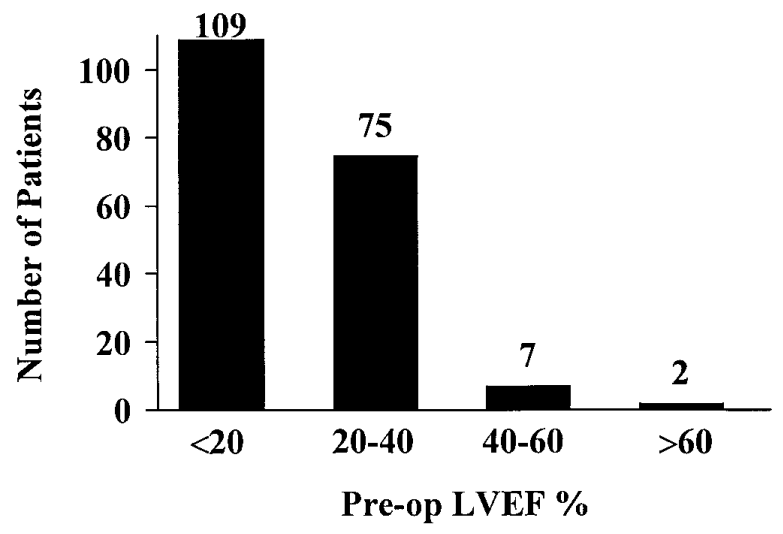

Fig 1. Histogram showing distribution of preoperative LVEF among our patient population.

nal infections, $2(1.0 \%)$ transient ischemic attacks, and $1(0.5 \%)$ stroke.

During follow-up, which extended to 14 years (mean $51 \pm 44$ months), there were 31 late deaths. Cause of death was congestive heart failure with or without MR in 19 patients, sudden death in 2 patients, death caused by ventricular arrhythmia in 2 patients, stroke in 1 patient, and cancer in 2 patients. Two patients died after a subsequent transplant, and 1 patient underwent mitral valve replacement and died postoperatively. The causes of 2 deaths were unknown.

The actuarial survival curve (including hospital deaths) is shown in Fig 2. Survival was $91 \%$ at 1 year, $89 \%$ at 2 years, $84 \%$ at 5 years, and $66 \%$ at 10 years. Among survivors, 5 patients required cardiac transplantation (mean interval, $36 \pm 32$ months). Five patients required pacemaker insertion for bradyarrhythmias, and 1 patient required an automatic implantable cardioverter defibrillator. According to multivariable analysis (Table I), predictors of poor 5-year result included preoperative echocardiographic evidence of MR of $2+$ or greater, symptoms of congestive heart failure, and ventricular tachycardia (VT). In our selected patients poor outcome was not related to age, sex, extent of coronary artery disease, EF, crossclamp time, or pump time. Because assessment of wall motion and ventricular volume was not available in all patients, we could not enter these variables into the model. However, $17(21 \%)$ of 80 patients with grossly enlarged hearts had poor results at 5 years versus 4 (8\%) of 48 patients with small hearts $(P=.040)$. Of 37 patients with dyskinesis, $3(9 \%)$ had a bad 5-year result versus $6(12 \%)$ of 50 of those with akinesis $(P=.556)$.

Among survivors, 123 (78\%) of 157 were symptomatically improved, with $64(41 \%)$ in symptom class 


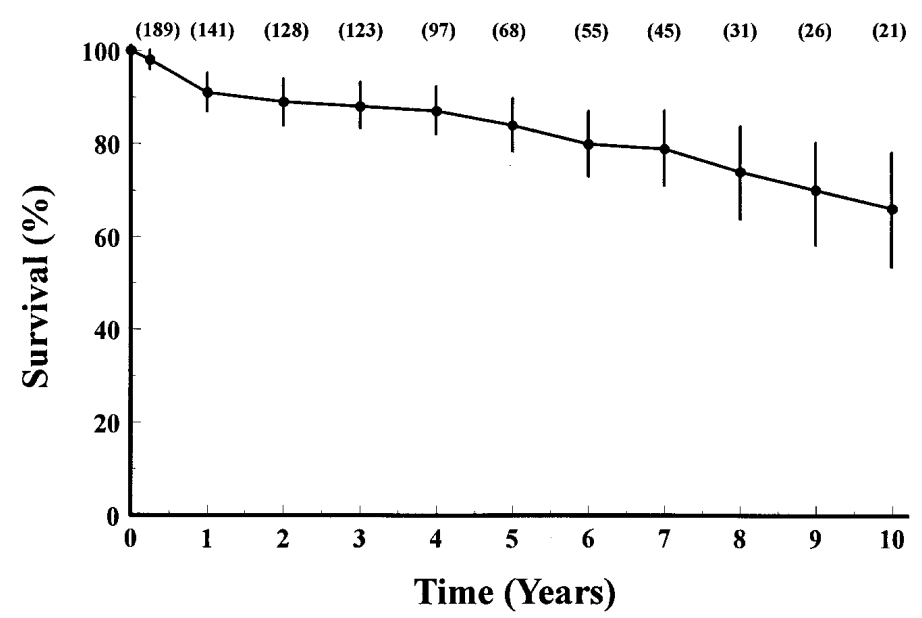

Fig 2. Actuarial survival after LV aneurysm resection. Figures in parentheses at the top indicate number of patients left at risk at that time of follow-up

Table I. Multivariable predictors of poor 5-year result by means of Cox regression analysis in patients undergoing repair of an LV aneurysm

\begin{tabular}{lcccc}
\hline Variable & Risk ratio & $95 \%$ CI & $\chi^{2}$ & P value \\
\hline Echocardiographic MR $\geq 2+$ & 2.94 & $1.3-6.6$ & 12.6 & .0004 \\
Congestive heart failure & 3.76 & $1.3-11$ & 8.6 & .0034 \\
VT & 2.34 & $1.1-5.0$ & 3.7 & .0539 \\
\hline
\end{tabular}

CI, Confidence interval.

I and $62(39 \%)$ in symptom class II. Fig 3 shows the change in symptom class for survivors (average increase, $1.4 \pm 1.0$ ). MUGA assessment preoperatively and postoperatively was available in 98 of the patients with an anterior aneurysm. There was a statistically significant increase in EF (determined by the paired $t$ test), with a mean change of $8.9 \% \pm 9.6 \%(P<.001)$. Preoperative and postoperative echocardiograms were performed in $123(64 \%)$ of 193 patients. Of these, 70 patients had $2+$ or more MR preoperatively. In 40 (57\%) of these patients, the MR was improved by at least 1 grade postoperatively (Fig 4).

\section{Discussion}

This article presents short- and long-term results achieved in a large series with aneurysm repair by means of a modified linear closure technique. The series includes patients with akinetic and dyskinetic aneurysms both large and small. We have outlined the selection criteria used in choosing patients for operative intervention. With this approach, we have achieved excellent surgical results, hospital mortality of only $2.6 \%$, and 5 -year survival of $84 \%$. Multivariate predic- tors of poor outcome at 5 years were preoperative MR of $2+$ or greater, congestive heart failure, and VT. In patients with volume data, marked ventricular enlargement also predicted a poor outcome.

In prior reports, operative mortality has been increased in patients with akinetic versus dyskinetic aneurysms. ${ }^{6,13,14}$ Furthermore, it has been suggested that only patients with clear-cut dyskinesis will benefit from aneurysm excision in terms of symptom relief, improved EF, and long-term survival. ${ }^{6,14}$ In our series 87 patients had detailed wall-motion analysis, which allowed their classification as akinetic or dyskinetic (appendix). There was no difference between the 2 groups with respect to basic patient characteristics. Two patients in the akinetic group died in the hospital, with no deaths in the dyskinetic group. Akinetic patients were more likely to need inotropic or intra-aortic balloon pump support postoperatively, but these differences did not reach statistical significance. Among survivors, the postoperative change in $\mathrm{EF}$ was greater in the dyskinetic group $(10.9 \% \pm 9.9 \%$ vs $5.7 \% \pm 10 \%)$, a difference that was almost statistically significant $(P=$ $.08)$. Nevertheless, patients in both groups experienced 


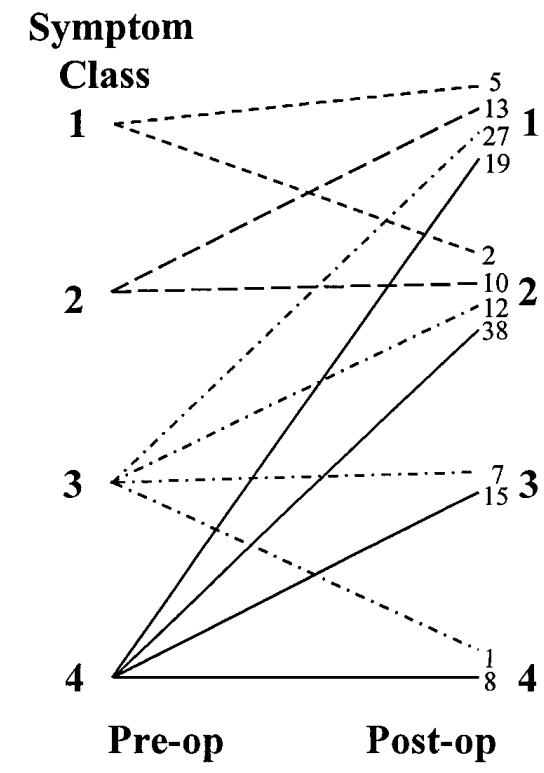

Fig 3. Preoperative and postoperative symptom class.

similar improvement in symptoms postoperatively, and 5-year survival was similar (91\% dyskinetic versus $94 \%$ akinetic). Our findings are in agreement with those reported by Dor and colleagues, ${ }^{5}$ who also showed no difference in preoperative variables, operating room mortality, improvement in symptoms, or long-term survival between the akinetic and dyskinetic groups.

An important aspect of our approach, especially in akinetic aneurysms, is assessment of wall thickness and function in the open-beating ventricle, which allows us to make decisions about resection versus revascularization without relying on viability studies. ${ }^{15}$ We agree with Suma and colleagues ${ }^{16}$ that in akinetic aneurysms the limits of scarring are not always well demarcated nor is the extent of endocardial scar a reliable indicator of the border between functioning and nonfunctioning wall. In these cases, palpation and assessment of regional wall motion in the unloaded beating heart are important to guide the extent of resection and repair. Furthermore, we believe, as does Jatene, ${ }^{2}$ that carrying out the repair on the beating heart has the advantages of minimizing ischemic time (crossclamp time, $60 \pm 24$ minutes) and facilitating decision making with regard to the need for a septal patch and optimal restoration of LV geometry. By resecting nonfunctioning wall, excluding aneurysmal portions of the septum, and plicating the length of the incision in the repair, we are attempting to decrease chamber dimensions, wall tension, and wall stress and to restore LV geometry toward normal.

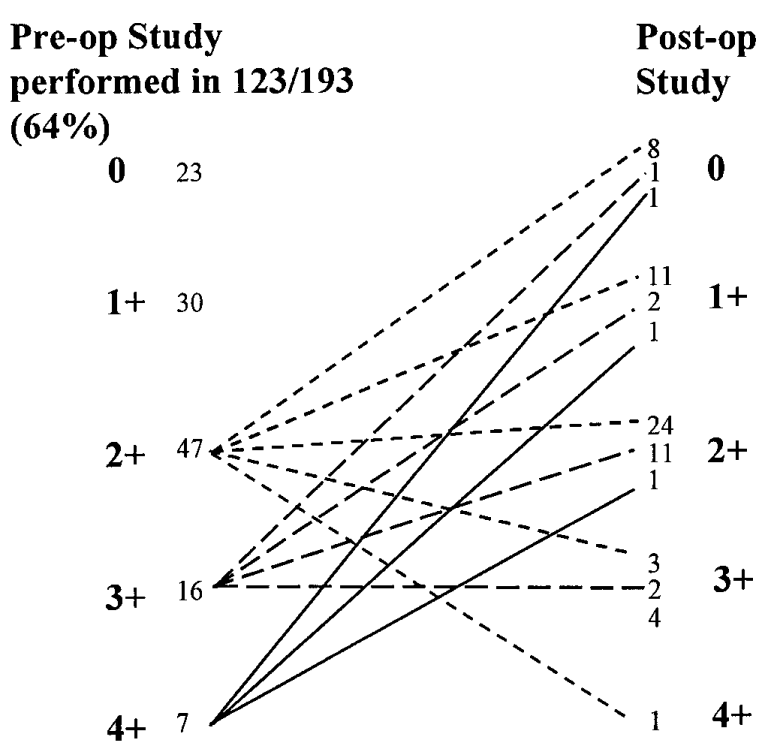

Fig 4. Results of preoperative and postoperative echocardiographic assessment of MR. MR has been graded on a scale of $1+$ to $4+$.

In our cases we have tailored scar excision to leave the left anterior descending artery for revascularization whenever possible, even if the distal vessel has been included in the repair. We believe that revascularization of even a small portion of the septum may be important in improving short- and long-term results. ${ }^{17,18}$

Our series includes a high proportion of patients with multivessel coronary disease, advanced LV dysfunction, and ventricular arrhythmias, factors that have been found in other series to be related to increased operative mortality. ${ }^{17,19-21}$ Nevertheless, our hospital mortality was low $(2.6 \%)$ compared with that in other recently reported aneurysm series, which range from $3 \%$ to $18 \% .{ }^{17,22-24}$ Clearly, case selection and operative technique may account for these differences.

In this series there were few perioperative complications. Only $18 \%$ of patients required intra-aortic balloon pump support versus $26 \%$ to $65 \%$ in other reported series. ${ }^{14,23}$ Few patients required reoperation for bleeding or sternal wound complications. There was only one stroke in this series. Like Elefteriades and colleagues, ${ }^{23}$ we believe that removal of endocardial thrombus before insertion of an LV vent has contributed to this low perioperative stroke rate.

In this series objective evidence of improved LV function after operation was provided by MUGA data. Our average increase in $\mathrm{EF}$ is similar to that reported in other series $(10 \%-14 \%){ }^{25-27}$ 
In considering patients for possible aneurysm repair, the issue of concomitant mitral insufficiency is an important one. During the time frame of this series, we were reluctant to undertake mitral valve replacement or repair in addition to revascularization and LV reconstruction. If severe MR was obvious, we tended to consider the patient's condition inoperable. However, preoperative Doppler echocardiography often indicated MR of 2+ when none was suspected on the angiogram, and 26 patients included in this series had MR of 3+ to $4+$. We went ahead with the operations in these selected cases because the severe MR was of relatively recent onset, with no evidence of recent myocardial infarction or chordal rupture. In these cases we believed that resection of the aneurysm would improve mitral function, which it did in $21(81 \%)$ of 26 . Possible mechanisms for this improvement include (1) decreased dilatation of the anulus caused by decreased ventricular size, (2) improved function of ischemic papillary muscles related to revascularization, or (3) realignment of papillary muscles related to improved geometry after ventricular repair. Of patients with a preoperative MR of $3+$ to $4+$, all but 2 are doing well at an average of 5.8 \pm 2.5 years postoperatively. In our multivariate analysis, however, the presence of MR of $2+$ or greater was found to be predictive of a poor 5-year result.

Recently, Bolling and colleagues ${ }^{28}$ have recommended mitral valvoplasty in patients with MR and decreased ventricular function. We are now using intraoperative transesophageal echocardiography to evaluate residual MR after completion of the ventricular repair. Whether the addition of an annuloplasty ring would further improve long-term results needs to be assessed.

After aneurysm resection, close follow-up and careful adjustment of medications is necessary to optimize symptomatic improvement. During follow-up, 8 patients were referred for additional procedures because of increasing congestive heart failure (7 transplants and 1 mitral valve replacement). Nevertheless, our 5-year survival was $84 \%$, which can be compared with survival in other reported series at 2 years $(86 \%)^{25}$ and at 5 years $(58 \%-70 \%) .{ }^{17,27}$

Pasini and colleagues ${ }^{17}$ reported an $8.6 \%$ incidence of sudden deaths after aneurysm repair. We used an aggressive approach in patients with ventricular arrhythmias, which includes map-directed or visually directed VT ablation, as previously described. ${ }^{11}$ In this series, during follow-up, there were 2 sudden deaths, 2 deaths related to ventricular arrhythmias, and 2 deaths of unknown cause. If we include the deaths of unknown cause, the mortality related to possible sudden death was only $3.1 \%$ (6/193). We believe that our vigorous approach to patients with ventricular arrhythmias explains this low incidence of sudden death. Nevertheless, preoperative VT was a predictor of poor outcome at 5 years. VT tends to occur in dilated hearts (45/80 [56\%] vs $13 / 48$ [27\%], $P=.001)$. We suggest that ventricular arrhythmias are a marker of more severe ventricular remodeling and a less favorable 5year prognosis.

In recent years, the number of patients referred for aneurysm resection has decreased in all but a few centers. ${ }^{22}$ This may be due in part to successful treatment of acute infarction with thrombolysis ${ }^{5}$ and preservation of epicardial muscle, which may prevent dyskinetic scar formation. After infarction, advances in medical treatment have proven effective in controlling symptoms of heart failure, and patients live longer before gross myocardial decompensation occurs. It is our experience, however, that once decompensation begins, deterioration may be rapid, and patients may die before appropriate investigation can be done and the possibility of surgical treatment entertained.

We agree with Dor and colleagues ${ }^{5,22}$ that akinesia and dyskinesia are part of the same process. Like Dor and colleagues, we recommend early repair because surgical risk in selected patients is low. If repair is delayed, contractile function of remote muscle may deteriorate with a progressive decrease in EF and dilatation of the heart. ${ }^{29,30}$ We have shown that gross dilatation and mitral insufficiency are predictors of a poor 5-year surgical result. We suggest that patients in whom aneurysms develop after infarction should be followed closely and considered for surgical treatment when signs of decompensation first occur, such as increasing symptoms with optimal medical management, or in asymptomatic patients if there is evidence of increasing ventricular volume or MR. Operations should be considered before these patients reach the stage when transplantation is the only reasonable option.

This series demonstrates that in selected patients resection of an akinetic or dyskinetic aneurysm and repair with a modified linear closure technique plus septoplasty when indicated can be done in the beating heart with a low operative mortality and provides good symptomatic improvement and excellent 5-year survival. The exact role of concomitant mitral annuloplasty in patients with an aneurysm and mitral insufficiency requires further investigation. 
Received for publication March 23, 2000; revisions requested June 20, 2000; revisions received Sept 7, 2000; accepted for publication Oct 30, 2000.

Address for reprints: Lynda L. Mickleborough, MD, EN 13-217 The Toronto Hospital, 200 Elizabeth St, Toronto, Ontario, M5G 2C4, Canada.

\section{REFERENCES}

1. Cooley DA, Collins HA, Morris GC, Chapman DW. Ventricular aneurysm after myocardial infarction: surgical excision with use of temporary cardiopulmonary bypass. JAMA 1958;167:557-60.

2. Jatene AD. Left ventricular aneurysmectomy. J Thorac Cardiovasc Surg 1985;89:321-31.

3. Dor V, Saab M, Coste P, Kornaszewski M, Montiglio F. Left ventricular aneurysm: a new surgical approach. J Thorac Cardiovasc Surg 1989;37:11-9.

4. Cooley DA. Ventricular endoaneurysmorrhaphy: a simplified repair for extensive postinfarction aneurysm. J Card Surg 1989;4:200-5.

5. Dor V, Sabatier M, Di Donato M, Montiglio F, Toso A, Maioli M. Efficacy of endoventricular patch plasty in large postinfarction akinetic scar and severe left ventricular dysfunction: comparison with a series of large dyskinetic scars. J Thorac Cardiovasc Surg 1998;116:50-9.

6. Mangschav A. Akinetic versus dyskinetic left ventricular aneurysms diagnosed by gated scintigraphy: difference in surgical outcome. Ann Thorac Surg 1989;47:746-51.

7. Mickleborough LL, Maruyama H, Liu P, Mohammed S. Results of left ventricular aneurysmectomy with a tailored scar excision and primary closure technique. J Thorac Cardiovasc Surg 1994;107:690-8.

8. DiCarli MF, Asganzadre F, Schelberth R, et al. Quantitative relation between myocardial viability and improvement in heart failure symptoms after revascularization in patients with ischemic cardiomyopathy. Circulation 1995;92:36-44.

9. Elfridi I, Grayburn PA, Panza JA, Oh JK, Zoghbi WA, Marwick TH. Myocardial viability during dobutamine echocardiography predicts survival in patients with coronary artery disease and severe left ventricular systolic dysfunction. J Am Coll Cardiol 1998;32:921-6.

10. Mickleborough LL. Left ventricular aneurysm: modified linear closure technique. In: JL Cox, Sundt TM III, editors. Operative techniques in cardiac and thoracic surgery: a comparative atlas. Vol 2. Philadelphia: WB Saunders; 1997. p 118-31.

11. Mickleborough LL, Usui A, Downar E, Harris L, Parson I, Gray G. Transtrial balloon technique for activation mapping during operations for recurrent ventricular tachycardia. J Thorac Cardiovasc Surg 1990;99:227-33.

12. Mickleborough LL, Maruyama H, Mohamed S, et al. Are patients receiving amiodarone at increased risk for cardiac operations? Ann Thorac Surg 1994;58:622-9.

13. Yannikas J, MacIntyre W, Underwood D, et al. Prediction of improvement in left ventricular function after ventricular aneurysmectomy using Fourier phase and amplitude analysis of radionuclide cardiac blood pool scans. Am J Cardiol $1985 ; 55: 1308-12$.
14. Couper GS, Bunton RW, Birjiniuk V, et al. Relative risks of left ventricular aneurysmectomy in patients with akinetic scars versus true dyskinetic aneurysms. Circulation 1990;82(Suppl):IV248-56.

15. Mickleborough LL, Carson S, Tamariz M, Ivanov J. Results of revascularization in patients with severe left ventricular dysfunction. J Thorac Cardiovasc Surg 2000;119:550-7.

16. Suma $\mathrm{H}$, Isomura $\mathrm{T}$, Horri $\mathrm{T}$, et al. Nontransplant cardiac surgery for end-stage cardiomyopathy. J Thorac Cardiovasc Surg 2000;119:1233-45.

17. Pasini S, Gagliardotto P, Punta G, et al. Early and late results after surgical therapy of postinfarction left ventricular aneurysm. J Cardiovasc Surg 1998;39:209-15.

18. Sinatra R, Macrina F, Braccio M, et al. Left ventricular aneurysmectomy; comparison between two techniques: early and late results. Eur J Cardiothorac Surg 1997;12:291-7.

19. Cosgrove DM, Lytle BW, Taylor PC, et al. Ventricular aneurysm resection: trend in surgical risk. Circulation 1989;79(Suppl):I-97-101.

20. Magovern GJ, Sakert T, Simpson K, et al. Surgical therapy for left ventricular aneurysms: a 10 year experience. Circulation 1989;79(Suppl):I-102-7.

21. Stephenson LW, Hargrove WC, Ratcliffe MB, Edmunds LH. Surgery for left ventricular aneurysm: early survival with and without endocardial resection. Circulation 1989;79(Suppl):I108-11.

22. Di Donato M, Sabatier M, Dor V, Toso A, Maioli M, Fantini F. Akinetic versus dyskinetic postinfarction scar: relation to surgical outcome in patients undergoing endoventricular circular patch plasty repair. J Am Coll Cardiol 1997;29:1569-75.

23. Elefteriades JA, Solomon LW, Salazar AM, Batsford WP, Baldwin JC, Kopf GS. Linear left ventricular aneurysmectomy: modern imaging studies reveal improved morphology and function. Ann Thorac Surg 1993;56:242-52.

24. Mills NL, Everson CT, Hockmuth DR. Technical advances in the treatment of left ventricular aneurysm. Ann Thorac Surg 1993;55:792-800

25. Grossi EA, Chinitz LA, Galloway AC, et al. Endoventricular remodelling of left ventricular aneurysm: Functional, clinical and electrophysiological results. Circulation 1995;92(Suppl):II-98100.

26. Kawata T, Kitamura S, Kawachi K, et al. Systolic and diastolic function after patch reconstruction of left ventricular aneurysms. Ann Thorac Surg 1995;59:403-7.

27. Shapira OM, Davidoff R, Hilkert RJ, et al. Repair of left ventricular aneurysm: long-term results of linear repair versus endoaneurysmorrhaphy. Ann Thorac Surg 1997;63:701-5.

28. Bolling SF, Pagani FD, Deals GM, Bash DS. Intermediate terms outcome of mitral reconstruction in cardiomyopathy. J Thorac Cardiovasc Surg 1998;115:381-6.

29. McKay RG, Pfeffer MA, Pasternak RC, et al. Left ventricular remodelling after myocardial infarction: a corollary to infarct expansion. Circulation 1986;74:693-702.

30. Pfeffer MA, Braunwald E. Ventricular remodelling after myocardial infarction: experimental observations and clinical implications. Circulation 1990;81:1161-72. 
Appendix. Classification of patients as akinetic or dyskinetic

\begin{tabular}{|c|c|c|c|}
\hline & Akinetic & Dyskinetic & $\mathrm{P}$ value \\
\hline Age (y) & $60 \pm 10$ & $59 \pm 9$ & .693 \\
\hline Male sex & $37 / 50(74 \%)$ & $32 / 37(87 \%)$ & .155 \\
\hline Anterior location & $42 / 50(84 \%)$ & $34 / 37(92 \%)$ & .274 \\
\hline Angina & $24 / 50(48 \%)$ & $18 / 37(49 \%)$ & .952 \\
\hline Congestive heart failure & $28 / 50(56 \%)$ & $22 / 37(60 \%)$ & .747 \\
\hline VT & $19 / 50(38 \%)$ & $19 / 37(51 \%)$ & .263 \\
\hline \multicolumn{4}{|l|}{ Symptom class } \\
\hline I & $2 / 50(4 \%)$ & $3 / 37(8 \%)$ & \multirow[t]{4}{*}{.235} \\
\hline II & $7 / 50(14 \%)$ & $6 / 37(16 \%)$ & \\
\hline III & $21 / 50(42 \%)$ & $8 / 37(22 \%)$ & \\
\hline IV & $20 / 50(40 \%)$ & 20/37 (54\%) & \\
\hline \multicolumn{4}{|c|}{ Extent of coronary artery disease } \\
\hline Single & $8 / 50(16 \%)$ & $8 / 37(22 \%)$ & \multirow[t]{3}{*}{.791} \\
\hline Double & $21 / 50(42 \%)$ & $14 / 37(38 \%)$ & \\
\hline Triple & $21 / 50(42 \%)$ & $15 / 37(41 \%)$ & \\
\hline \multicolumn{4}{|l|}{$\mathrm{EF}$} \\
\hline$>40 \%$ & $1 / 50(2 \%)$ & $3 / 37(8 \%)$ & \multirow[t]{3}{*}{.188} \\
\hline $20 \%-40 \%$ & $21 / 50(42 \%)$ & $10 / 37(27 \%)$ & \\
\hline$<20 \%$ & $28 / 50(56 \%)$ & $24 / 37(65 \%)$ & \\
\hline MR 2+ or more & $28 / 45(62 \%)$ & $21 / 34(62 \%)$ & .967 \\
\hline Asynergy (\%) & $58 \pm 16$ & $61 \pm 12$ & .335 \\
\hline Crossclamp time (min) & $58 \pm 24$ & $59 \pm 27$ & .909 \\
\hline Pump time (min) & $158 \pm 44$ & $174 \pm 53$ & .137 \\
\hline Patients grafted (\%) & $47 / 50(94 \%)$ & $33 / 37(89 \%)$ & .415 \\
\hline Average No. of grafts & $3.0 \pm 1.1$ & $2.8 \pm 1.1$ & .667 \\
\hline Use of LITA & $26 / 50(52 \%)$ & $14 / 37(38 \%)$ & .190 \\
\hline Patch septoplasty & $6 / 50(12 \%)$ & $9 / 37(24 \%)$ & .132 \\
\hline IABP & $13 / 50(26 \%)$ & $6 / 37(16 \%)$ & .275 \\
\hline Inotropeic agents & $30 / 50(60 \%)$ & $17 / 37(46 \%)$ & .193 \\
\hline Hospital mortality & $2 / 50(4 \%)$ & $0 / 37(0 \%)$ & .218 \\
\hline Improved symptoms & $38 / 48(79 \%)$ & $25 / 33(76 \%)$ & .717 \\
\hline Preoperative symptom class & $3.2 \pm 0.8$ & $3.2 \pm 1.0$ & .854 \\
\hline Postoperative symptom class & $1.7 \pm 0.9$ & $1.8 \pm 0.9$ & .494 \\
\hline LVEDP & $23.3 \pm 8.7$ & $21.8 \pm 5.9$ & .497 \\
\hline Change in $\mathrm{EF}$ & $5.7 \pm 10.2$ & $10.9 \pm 9.9$ & .080 \\
\hline
\end{tabular}

LITA, Left internal thoracic artery; IABP, intra-aortic balloon pump; LVEDP, left ventricular end-diastolic pressure. 